\title{
EPS Nuclear Winter Workshop, Geneva 1986
}

\author{
D. Parkinson, Malvern
}

(Chairman EPS Advisory Committee on Physics and Society)

A Workshop on the climatic changes that could be provoked by a nuclear war was held in Geneva in October 1986, attended by invited delegates from eastern Europe (14), western Europe (13), members of the EPS Advisory Committee on Physics and Society (5) and the President of EPS. The delegates came from all the principal disciplines that are involved viz.: Physics, Atmospheric Science, Computer Modelling, Medicine, Ecology, Biology and Botany.

The objects of the Workshop were to: a) review the known information on the factors which could govern climatic changes resulting from a nuclear exchange;

b) attempt to specifiy those aspects of the problem on which more work should be done;

c) specify, if possible, topics suitable for East-West collaboration.
Eight of the delegates had worked extensively on the SCOPE-ENUWAR project, the findings of which ${ }^{1}$ ) figured heavily in the discussions. These fell into three parts; the physics and "mechanics" of what was likely to occur; biological and botanical effects; general discussions and conclusions.

\section{Physical Aspects}

While it is possible that a nuclear war on a limited scale could occur it seems very difficult to avoid escalation to a large scale. Consequently, the Workshop adopted the scenario used in the Scope studies which assumed the explosion of warheads yielding $6000 \mathrm{Mt}$ TNT equivalent corresponding to the detonation of $40 \%$ of the world's arsenal of 50000 warheads; the remainder are assumed to have suffered malfunction. destruction or not to have been fired.

\section{International Symposium on the}

\section{TECHNOLOGIES FOR OPTOELECTRONICS}

\section{6-20 November 1987 \\ Palais des Festivals et des Congrès \\ Cannes, France}

Organized by

ANRT-Association Nationale de la Recherche Technique

SPIE-The International Society for Optical Engineering

Cooperating Sponsors

Associazione Elettrotecnica ed Elettronica Italiana

Austrian Physical Society

Battelle-Geneva Research Centres Comité Belge d'Optique

DGaO-Deutsche Gesellschaft für angewandte Optik

European Physical Society in

collaboration with its Optics Division

Israel Laser and Electro-Optic Society

Optics Division/Portuguese Physical

Society

Promoptica

SEE-Société Française des

Electriciens, des Electroniciens et des Radioélectriciens

SGOEM-Schweizerische Gesellschaft für Optik und Elektronenmikroskopie

Sira Ltd-The Research Association for Instrumentation

Société Française d'Optique

\section{EIGHT CONFERENCES}

Quantum Wells and Superlattices in Optoelectronic Devices and Integrated Optics

Real Time Image Processing: Concepts and Technologies

Materials and Technologies for Optical Communications Devices

Focal Plane Arrays: Technology and Applications

Ultraviolet Technology

Optical Devices in Adverse Environments

Advanced Optoelectronic Technology

Optical Interconnections

TUTORIAL EDUCATION PROGRAM TECHNICAL INSTRUMENT EXHIBIT
The existing nuclear arsenals are for the most part in the northern hemisphere roughly between the Tropic of Cancer and the Arctic Circle. All the likely prime targets lie within these latitudes where $80 \%$ of the world's population live and the greatest food producing areas are established.

The first problem to be studied at the Workshop was the quantity of dust and smoke likely to be thrown into the atmosphere and their effect on insolation. Dust is created predominantly by nuclear ground bursts that would probably be used at a power of about $1 \mathrm{Mt}$ against hardened military targets (silos etc.). Such bursts throw up large quantities of debris even into the stratosphere. Of particular concern are particles of a size between 0.1 and $1 \mu \mathrm{m}$ which are the most effective in scattering and absorbing light. Allowing for fallout, rainout, etc., the likely quantity of dust thrown up "above the weather" in this size range could be some $40 \mathrm{Tg}$, and this could remain in the upper atmosphere for many months.

Attacks on cities and the infrastructure of a country are more effectively made with air bursts of a power of about $0.1 \mathrm{Mt}$ or less. At these powers, the blast effects and ignition zone per $\mathrm{Mt}$ are maximised aided by increased targetting precision. To estimate the amount of smoke produced by the consequent city fires, it was assumed that the U.S.A. carried out its notional plan of targetting the 200 largest Soviet cities and $80 \%$ of the towns with populations greater than 2 $\times 10^{4}$, and the USSR did the same in the western countries. The ignition zone of an air burst may be defined as that region in which the thermal flux is greater than $12 \mathrm{cal} / \mathrm{cm}^{3}$. In the core areas of cities, the quantity of combustibles of all kinds could be as high as $40 \mathrm{~kg} / \mathrm{m}^{2}$ while in the surrounding and suburban areas it would be much less. The fraction burned and converted into smoke could be, say, $10 \%$ and the proportion of smoke which is black, graphitic (sooty) and of a size between 0.1 and $1 \mu \mathrm{m}$ of the same order. It is known that the smallest particles agglomerate towards this size range and that larger par- 
ticles suffer fallout. There are many factors which have to be taken into account here: oil and fossil fuel derivatives (plastics) produce more smoke than wood for example; the intensity of the fires, ventilation and oxygen supply all have a bearing. Nevertheless, using the $10 \%$ figures suggested, there could be some $40 \mathrm{Tg}$ of graphitic smoke produced in the relevant size range.

If it is assumed that this quantity of smoke was spread evenly around the northern hemisphere between the latitudes of $30^{\circ}$ and $60^{\circ}$ North, the density would be $0.3 \mathrm{~g} / \mathrm{m}^{2}$ giving an absorption optical depth of 4 . This implies that only about $1 \%$ of the sunlight, travelling vertically would reach the Earth's surface. Because cities are the most important source, the smoke distribution would be patchy, but in the affected zones, light would be reduced to zero. Evidently significant climatic effects would be provoked. Other sources of smoke such as forest and scrub land fires, although big, can be neglected in comparison with the burning cities. Even the dust can be neglected by comparison because the particles give rise to mostly forward scattering.

This over-simple analysis needs to be refined: the height of injection of the smoke, its drift and sideways spreading, etc. have to be estimated and computer models made to calculate the resultant temperature changes. Considerable differences must be expected between the summer (greater) and winter (smaller) temperature falls. Nevertheless, in spite of the uncertainties, even with very conservative figures it could be concluded that temperature falls of several degrees would be experienced over the northern hemisphere.

\section{Bio-effects}

In the second part of the Workshop the likely effects on vegetation and animal life were considered. First, the human survivors of a large scale nuclear war would have to face the near-complete destruction of the normally accepted infrastructure in the target cities. The people would be weakened in time by radiation sickness and open to disease. Food and shelter would be their primary concern.

In the discussions of the botanical and agricultural effects of a combination of a decrease in temperature and light, attention was brought to focus inevitably on the most important crops - wheat, maize, rice, etc. It is known that these (particularly the modern hybrids) are very sensitive to light reduction during their rapid growth periods. Experiments have shown that a reduction in light to $1 \%$ of normal for two weeks in the growing period is enough to reduce the yield of wheat to negligible levels. It has been estimated that if the mean summer temperature in Canada was reduced by 1 $\operatorname{deg} \mathrm{C}$ only, the Canadian wheat harvest would fall by about $46 \%$.

There are few data to enable estimates to be made of the effects of the combined stresses of a reduction in light and a reduction in temperature. Similarly little is known of the effects of fairly rapidly fluctuating variations of light and temperature as would be experienced under patchy smoke clouds. We know, however, that rice, maize and sorghum, because they have become acclimatised to stable habitats by natural selection, are particularly sensitive to temperature reductions in their growing season as well as to light reductions.

From the human point of view, the most important animal survivors would be farm livestock. But they would be in the same situation as humans, suffering from radiation sickness and lack of feed stuffs. Such meat as may be available would be contaminated by radiation well above the normally accepted levels for many months. Fishing does not provide a way out. Strong temperature gradients between the land and oceans arising in a nuclear war aftermath would almost certainly produce heavy storm conditions in coastal regions and lakes would be contaminated by radioactive fallout and other pollutants. At sea one can consider three ecosystems: esturine, continental shelf and deep ocean. The effects of light reduction on the food chain ranging from phytoplankton to fish have to be considered. In esturine regions, pollution of all kinds would reduce the likelihood of useful food production to negligible proportions. The outlook for the other systems is not good because of the effects on the food chain base, the phytoplankton.

In turning to the longer term effects and particularly those concerned with the life cycle of plants, there are many unknown factors. Whilst it might be thought that the immediate acute phase after a nuclear exchange would exert the greatest influence on plant life, it is quite possible that prolonged stresses at lower levels would be more serious. Many species for example adapted to a mediterranean climate, could survive the acute phase as bulbs or dormant seeds, but might not be able to modify their life cycles to cope with a different pattern of wet-cool and hot-dry seasons, both of which are essential for plant development. A prolonged climatic change could well lead to total failure. Other factors must also be considered: the potential explosion of insect herbivores in the absence of predators and the inevitable suspension of insecticide treatment; the probable outbreak of fungal diseases; etc.

\section{Conclusions}

Discussions in the Workshop revealed an extensive list of topics on which further work must be done, and these are set down in full in the Report ${ }^{2}$ ). In addition, the following general conclusions were drawn:

a) There is sufficient evidence for believing that after a large scale nuclear war in the northern hemisphere, there would be enough smoke and dust in the atmosphere to depress ground temperatures over much of the hemisphere by several degrees Celsius at least, and to reduce light levels to less than $5 \%$ of normal for periods of weeks to months. The possibility of longer term perturbations cannot be excluded.

b) If nuclear war was waged in the growing season, the initial stress would be sufficient to ensure that there was no harvest of cereals, rice, sorghum etc. in the northern hemisphere. If in the winter half-year, the effect in middle latitudes might not be so extreme, but the consequences for agriculture in low latitudes would still be devastating.

c) There are major uncertainties particularly over the time during which the effects would be significant, which cannot be resolved without a major collaborative effort between scientists from many different fields. In this collaboration, physicists have an important role to play.

A summary of the Workshop similar to the above has been sent to national societies and members of the Advisory Committee on Physics and Society with a view to their giving it wide publicity. The Report as such, comprising some 48 pages including the appendices has been printed by the University of East Anglia and sent to the same groups plus members of Council. Further copies will be available from the Secretariat.

The Report will form the basis for the discussion to be held on Tuesday 11 August, 1987 during the 7th EPS General Conference in Helsinki.

\section{REFERENCES}

1. SCOPE 28: Vol. 1, Physical and Atmospheric Effects; Vol. 2, Ecological and Agricultural Effects (Wiley, Chichester, UK) 1986.

2. Nuclear Winter Workshop, Geneva 1986 (European Physical Society, Geneva) 1987. 